Opinion

\title{
A wake up call to men \& the women who care about them
}

\section{Opinion}

MEN, are you aware that one of every seven of you have or will have prostate cancer? Are you aware that one of you dies of prostate cancer every thirteen minutes? Are you aware that one of the primary reasons for this startling figure is because you men fail to recognize the threat of prostate cancer and precipitate this problem by failing to get a prostate examination at the very minimum of every year? And are you aware that African-American men have the world's highest incidence of prostate cancer as well as experience the higher incidence of dying of prostate cancer? For these men and any man with a family history of prostate cancer, annual testing becomes more necessary and important to be aware of the presence of this disease and early treatment before it becomes aggressive in development.

Men with a family history of prostate cancer or breast cancer and African-American men should begin this annual examination at 35 years of age. Other men should begin at 40 years of age. National figures suggest this can wait until 40 or 50 years of age, but the fact of the matter is that too many men are presenting with already metastasized prostate cancer (spread outside the prostate) by the time they have reached these ages. Dying because of prostate cancer is not a pleasant experience and, most importantly, is avoidable! If you care about yourself, if you care about your family and loved ones, you will recognize the importance of this message.

WOMEN, we need YOU to encourage your husbands, sons, brothers, fathers and male friends to recognize this threat and get to a physician for that annual examination.

Once you men begin receiving that annual Prostate-Specific Antigen (PSA) blood test and Digital Rectal Examination (DRE), get a copy of the results for your own records and keep track along with your physician on the level of rise of that PSA test each year to be able to personally recognize that even though it may be of a low level, that if it is increasing in velocity at a rate of just $0.75 \mathrm{ng} / \mathrm{ml}$ in a year (e.g. $2.0 \mathrm{ng} / \mathrm{ml}$ this year, $3.0 \mathrm{ng} / \mathrm{ml}$ next year) or doubling at a rate less than twelve years (e.g. $2.0 \mathrm{ng} / \mathrm{ml}$ this year, 2.5 next year, but $4.0 \mathrm{ng} / \mathrm{ml}$ the following year (doubled in just two years)), it is important to then visit a specialist in urology since these are indicators of possible prostate cancer development.

Once diagnosed, you rarely need to be, and should not be by your physician, rushed to immediate treatment. If you have not already
Volume 4 Issue 4 - 2016

Charles Maack

US Too International Inc, USA

Correspondence: Charles Maack, US Too International Inc, 5003 Fairview Ave, Downers Grove, IL 605I 5, USA, Email maackl@cox.net

Received: March 0I, 2016 | Published: April 04, 2016

done so, take reasonable time to educate yourself in the many therapies available to treat this insidious disease. You then can be an educated and valuable partner with your physician in getting the treatment with which you would be most comfortable. If you are uncomfortable with the recommended therapy of your physician, get a second opinion from another physician. Most all health insurance programs cover the cost of this second opinion.

I am personally a man who is a prostate cancer survivor since 1992 and still a continuing prostate cancer patient. I have experienced several therapies to combat this disease and my ardent desire is to educate men BEFORE they are diagnosed with prostate cancer on the absolute importance of nutrition and physical activity that might prevent prostate cancer, annual PSA and DRE examination to check on prostate abnormalities, early detection should an abnormality exist, and then early treatment towards a hopeful cure. Early detection can equate to effective treatment; late detection can result in many complications.

\section{Conflicts of Interest}

The authors declare no conflict of interest.

\section{Acknowledgments}

None.

Funding

None. 